\title{
Post-cracking behaviour of steel fibre reinforced concrete
}

\author{
J.A.O. Barros, V.M.C.F. Cunha, A.F. Ribeiro and J.A.B. Antunes \\ Dep. of Civil Eng., School of Eng., Univ. of Minho, Campus de Azurém, 4810-058 Guimarães, Portugal
}

Received: December 23, 2003; accepted: February 24, 2004

\begin{abstract}
Recently, RILEM TC 162-TDF has proposed equivalent, $f_{\text {eq }}$, and residual, $f_{R}$, flexural tensile strength parameters to characterize and simulate the post-cracking behaviour of steel fibre reinforced concrete (SFRC) structures. In the current work, more than two hundred flexural tests are carried out according to the RILEM TC 162-TDF recommendations and the corresponding values of $f_{e q}$ and $f_{R}$ parameters are evaluated. In series of specimens reinforced with fibres of a distinct length/diameter ratio, similar values of $f_{e q}$ and $f_{R}$ parameters were obtained in these series. Although a strong correlation between $f_{e q}$ and $f_{R}$ was determined, a larger scatter of $f_{R}$ values was observed thereby revealing $f_{e q}$ to be more appropriate for design purposes. A numerical strategy involving a cross sectional layered model and an inverse analysis was developed to evaluate the post-cracking stress-strain and the stress-crack opening diagrams for the tested SFRC. This strategy was also used to determine a relation between the post-cracking strain, $\varepsilon^{p c r}$, and the crack opening displacement, $w,\left(\varepsilon^{p c r}=w / L_{p}\right)$ which is useful for evaluating the crack opening when numerical strategies based on a stress-strain approach are used. The obtained $L_{p}$ values range from half the specimen cross section height to half the distance between the tip of the notch and the top of the cross section.

1359-5997 (C) 2004 RILEM. All rights reserved.

\section{RÉSUMÉ}

Récemment, pour caractériser et simuler le comportement post-fissuration en traction du béton renforcé des fibres d'acier, la Commission Technique 162-TDF de la RILEM a proposé des paramètres désignés par résistance équivalente, $f_{e q}$, et résistance résiduelle, $f_{R}$ à la contrainte en flexion. Dans le travail présent, des valeurs de ces paramètres sont obtenues sur plus de deux cents essais de flexion effectués en accord avec les recommandations du TC 162-TDF de la RILEM. Des valeurs semblables de $f_{e q}$ et $f_{R}$ ont été obtenues dans des séries d'éprouvettes renforcées avec des fibres d'un rapport longueur/diamètre distinct. Bien qu'une forte corrélation entre $f_{e q}$ et $f_{R}$ ait été déterminée, une plus grande dispersion de valeurs du $f_{R}$ a été observée, en démontrant que $f_{\text {eq }}$ est plus approprié pour les buts du projet. Pour évaluer les diagrammes contrainte-déformation et contrainteouverture après fissuration, une stratégie numérique a été développée, en utilisant un modèle de section et en effectuant une analyse inverse. Cette stratégie a aussi été utilisée pour déterminer une relation entre la contrainte après fissuration, $\varepsilon^{p c r}$, et l'ouverture de fissure, $w,\left(\varepsilon^{p c r}=w / L_{p}\right)$ utile pour évaluer l'ouverture de la fissure quand les stratégies numériques sont basées sur une approche contrainte-déformation. Les valeurs de $L_{p}$ obtenues ont varié entre la demi-hauteur de la section de l'éprouvette et la demi-distance entre l'extrémité de l'entaille et le sommet de la section.
\end{abstract}

\section{INTRODUCTION}

The energy dissipated in concrete cracking is the property most benefited from the addition of fibres to concrete. To characterize toughness enhancement provided by fibre reinforcement mechanisms, ASTM C 1018 [1] recommended the use of toughness indexes, $I_{N}$, and residual strength factors, while the Japanese Society of Civil Engineers (JSCE) proposed the concept of the flexural toughness factor, $F T$ [2]. Gopalaratnam et al. [3] and Banthia and Trottier [4, 5] pointed out the deficiencies of the aforementioned two approaches: the $I_{N}$ of ASTM C 1018 are susceptible to human judgment errors, since they require an accurate assessment of the crack initiation, which is almost impossible; the FT of JSCE is dependent on specimen geometry and the limit deflection of span/150 (mm) used in its calculation is not based on serviceability considerations. Using a test set-up identical to JSCE, Banthia and Trottier [4] proposed the concept of post-crack strength, PCS. The main contributions of this technique are the exclusion of the energy up to peak load (energy not influenced by fibre reinforcement) from the total energy up to given deflections, and the consideration of various deflection limits to cover distinct requirements on serviceability limit state analysis.

The recommendations of RILEM TC 162-TDF to characterize the post-cracking behaviour of SFRC $[6,7]$ can be regarded as an improvement of the technique proposed by Banthia and Trottier [4]. To decrease the scatter in the values 
generally reported when using four-point unnotched beam tests (like JSCE and Banthia and Trottier test set up), RILEM TC162-TDF proposed a three-point notched beam test. Since plain concrete shows a strain-softening phase, RILEM TC 162-TDF recommended a more precise procedure for excluding the parcel of energy due to matrix cracking from the total energy absorbed by a SFRC. Furthermore, two deflection limits were used for the evaluation of the equivalent flexural tensile strength parameters, one to be used on the design at serviceability limit states, $f_{e q, 2}$, and the other on the design at ultimate limit states, $f_{e q, 3}$ [7]. The $f_{\text {eq }}$ concept corresponds to FT of JSCE and PCS of Banthia and Trottier inasmuch as it is a function of the energy dissipated up to a given deflection. It deviates from $F T$ and $P C S$, however, since $f_{e q}$ is presumed to only take the energy absorption capacity provided by fibre reinforcement mechanisms. More recently, RILEM TC 162TDF proposed the replacement of $f_{e q}$ for the concept of residual flexural tensile strength, $f_{R}$, which gives the stress for distinct deflections or crack mouth opening displacements, (CMOD) [8]. Although this last concept has the advantage of being easier to evaluate, it is more susceptible to the irregularities of the force-deflection relationships registered in the tests. The $f_{e q}$ and $f_{R}$ parameters were also used to define the stress-strain constitutive law proposed for modelling the post cracking behaviour of SFRC [7, 9].

To characterize the SFRC post-cracking behaviour according to RILEM TC 162-TDF recommendations, an experimental and a numerical research were carried out in the present work. In the experimental part, the values of $f_{e q}$ and $f_{R}$ parameters were determined and the distribution of the steel fibres on the fracture surface of the tested specimens was also evaluated for estimating its influence on the mix workability, load-deflection response $(F-\delta)$ and on the values of the $f_{e q}$ and $f_{R}$ parameters. To assess whether $f_{R}$ can replace $f_{\text {eq }}$, these parameters were correlated using the results obtained in the experimental program. The numerical research was composed by the development of a computational code with two approaches for modelling the post cracking behaviour: the stress-strain, $\sigma-\varepsilon$, and the stress-crack opening, $\sigma$-w, methods. The suitability of the post cracking $\sigma-\varepsilon$ relationship proposed by RILEM TC 162-TDF [9] was analysed. An inverse analysis was also performed for evaluating the $\sigma-w$ trilinear diagram for the designed SFRC. Finally, a relationship between post cracking strain and crack opening displacement was obtained, which may be useful for estimating the crack opening when numerical strategies based on $\sigma-\varepsilon$ approaches are used.

\section{CONCEPTS OF EQUIVALENT AND RESIDUAL FLEXURAL TENSILE STRENGTH PARAMETERS}

The specimen geometry, the method for casting the specimens, the curing procedures, the position and dimensions of the notch sawn into the specimen, the loading and specimen support conditions, the characteristics for both the equipment and measuring devices, and the test procedures recommended by RILEM TC 162-TDF to characterize the flexural behaviour of SFRC are all given elsewhere [8].
A force deflection relationship, $F-\delta$, similar to those depicted in Figs. 1 and 2 is obtainable from a bending test. If a clip gauge is mounted at the notch mouth, a force crack mouth opening displacement relationship, $F$-CMOD, can also be recorded. Using these relationships, RILEM TC 162-TDF proposed the evaluation of the load at the limit of proportionality $\left(F_{L}\right)$, the equivalent $\left(f_{e q, 2}\right.$ and $\left.f_{e q, 3}\right)$ and the residual $\left(f_{R, 1}\right.$ and $\left.f_{R, 4}\right)$ flexural tensile strength parameters $[6,8]$. $F_{L}$ is the highest value of the load recorded up to a deflection (or CMOD) of $0.05 \mathrm{~mm}$. The parameters $f_{e q, 2}$ and $f_{e q, 3}$ are related to the material energy absorption capacity up to a deflection of $\delta_{2}$ and $\delta_{3} \quad\left(\delta_{2}=\delta_{L}+0.65 \mathrm{~mm}\right.$ and $\delta_{3}=\delta_{L}+2.65 \mathrm{~mm}$, where $\delta_{L}$ is the deflection corresponding to $\left.F_{L}\right)$ provided by fibre reinforcement mechanisms $\left(D_{B Z, 2}^{f}\right.$ and $D_{B Z, 3}^{\prime}$ ), as seen in Figs. 1 and 2. The parcel of the energy due to matrix cracking $\left(D^{b}{ }_{B Z}\right)$ is not considered in the $f_{e q}$ evaluation. The parameters $f_{R, I}$ and $f_{R, 4}$ are the stresses for the forces $F_{R, 1}$ and $F_{R, 4}$, respectively, at deflection of $\delta_{R, 1}=0.46 \mathrm{~mm}$ and $\delta_{R, 4}=$ $3.0 \mathrm{~mm}$. According to RILEM TC 162-TDF, the equivalent [6] and the residual [8] flexural tensile strength parameters are obtained from the following expressions:

$$
\begin{aligned}
& f_{e q, 2}=\frac{3}{2} \frac{D_{B Z, 2}^{f}}{0.50} \frac{L}{b h_{s p}^{2}} ; f_{e q, 3}=\frac{3}{2} \frac{D_{B Z, 3}^{f}}{2.50} \frac{L}{b h_{s p}^{2}}\left[\mathrm{~N} / \mathrm{mm}^{2}\right] \\
& f_{R, 1}=\frac{3}{2} \frac{F_{R, 1} L}{b h_{s p}^{2}} ; f_{R, 4}=\frac{3}{2} \frac{F_{R, 4} L}{b h_{s p}^{2}}\left[\mathrm{~N} / \mathrm{mm}^{2}\right]
\end{aligned}
$$

where $b(=150 \mathrm{~mm})$ and $L(=500 \mathrm{~mm})$ are the width and the span of the specimen, and $h_{s p}(=125 \mathrm{~mm})$ is the distance between the tip of the notch and the top of the cross section.

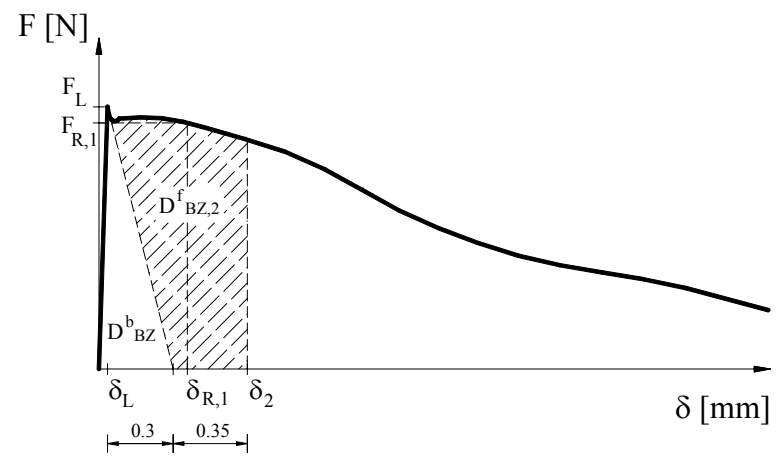

Fig. 1 - Evaluation of $f_{e q, 2}$ and $f_{R, 1}$ flexural tensile strength parameters according to RILEM TC 162-TDF $[6,8]$.

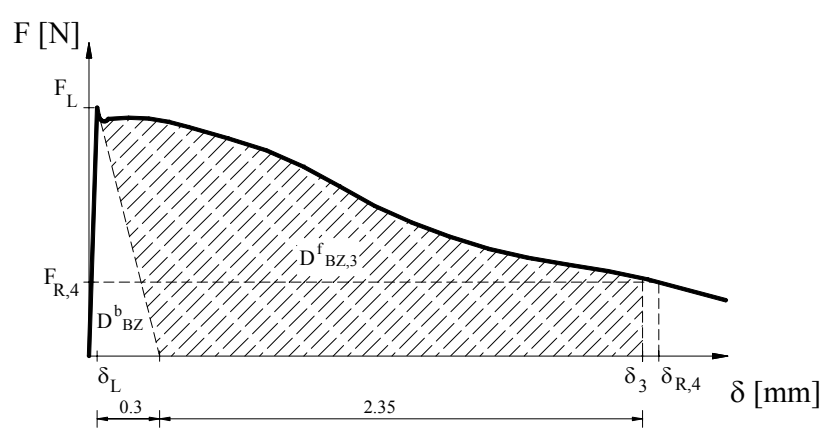

Fig. 2 - Evaluation of $f_{e q, 3}$ and $f_{R, 4}$ flexural tensile strength parameters according to RILEM TC $162-\mathrm{TDF}[6,8]$. 


\section{EXPERIMENTAL RESEARCH}

\subsection{Materials and compositions}

An SFRC was designed abiding by the following conditions: average compressive strength greater than $25 \mathrm{MPa}$ at 28 days; binder content (cement + fly ash) equal to $300 \mathrm{~kg} / \mathrm{m}^{3}$; slump greater than $150 \mathrm{~mm}$; and use of local and untreated aggregates. The strength and the workability requirements were adjusted for an SFRC that could be used in several structural applications, such as partial replacement of conventional reinforcement by steel fibres and slabs on grade. Two types of hooked ends DRAMIX ${ }^{\circledR}$ steel fibres were used: $\mathrm{RC} 80 / 60 \mathrm{BN}$ (designated in this work by F80/60) with a length $\left(l_{f}\right)$ of $60 \mathrm{~mm}$, a diameter $\left(d_{f}\right)$ of $0.75 \mathrm{~mm}$ and an aspect ratio $\left(l_{f} / d_{f}\right)$ of 80 ; RC $65 / 60 \mathrm{BN}$ (designated in this work by $F 65 / 60$ ) with $l_{f}=60 \mathrm{~mm}, d_{f}=0.92 \mathrm{~mm}$ and $l_{f} / d_{f}=65$. Both fibres have a yield stress of about $1100 \mathrm{MPa}$. The compositions are given elsewhere [10].

\subsection{Compressive strength}

Preliminary tests had shown that by increasing the percentage of cement replaced by fly ash, $F a$, the mix workability increased and the concrete strength decreased. Therefore, in order to obtain similar compressive strength and mix workability in all compositions, the water/binder ratio $(w / b)$ was decreased with the increase of the percentage of cement replaced by $\mathrm{Fa}$. Table 1 reveals that, in terms of compressive strength, $f_{c m}$, the influence of $F a$ was only significant in seven-day-old specimens. The influences of the type and fibre content on $f_{c m}$ were marginal.

\subsection{Fibre distribution on the fracture surface}

Apart from very specific applications, RILEM TC 162TDF recommends that the loading direction of the specimen should be orthogonal to its casting direction [8]. The SFRC designed in the present work had high workability, which could promote significant fibre segregation during the specimen compaction procedure. To evaluate the degree of fibre segregation, the specimen fracture surface was discretized in cells to ascertain the fibre distribution on its surface [10]. According to [11], a hooked ends steel fibre is

\begin{tabular}{|c|c|c|}
\hline \multicolumn{3}{|c|}{$\begin{array}{l}\text { Table } 1 \text { - Influence of the percentage of cement } \\
\text { replaced by } F a \text { on the compressive strength }\end{array}$} \\
\hline Age [days] & $\mathrm{Fa}^{*}[\%]$ & $f_{c m}^{* *}[\mathrm{MPa}]$ \\
\hline \multirow{3}{*}{7} & 0.0 & 37.0 \\
\hline & 12.5 & 30.1 \\
\hline & 25.0 & 26.5 \\
\hline \multirow{3}{*}{28} & 0.0 & 39.7 \\
\hline & 12.5 & 39.3 \\
\hline & 25.0 & 34.8 \\
\hline \multirow{3}{*}{90} & 0.0 & 47.2 \\
\hline & 12.5 & 46.6 \\
\hline & 25.0 & 45.5 \\
\hline
\end{tabular}

effective in terms of pullout resistance if its embedment length is greater than the length of its hooked end. Adopting this criterion, an increase of the fibre percentage in the casting direction was observed in the tested specimens [10]. This fibre segregation was more pronounced in specimens reinforced with $F 80 / 60$ fibres, and promoted the development of non uniform crack opening [10]. For SFRC of high workability placed with some vibration, fibre segregation has, therefore, a high probability to occur. In this case, the post cracking behaviour of the SFRC specimens is largely dependent on the loading direction, which should simulate, as much as possible, the loading of the real application. The compaction procedure for the specimens should also replicate, as closely as possible, the compaction practice adopted in the real application.

Fig. 3 presents the relationship between the content of fibres, $C_{f}$, and the number of fibres, $N_{f}$, counted on the fracture surface of the tested specimens. As was expected, $N_{f}$ increased with $C_{f}$ and was greater in series reinforced with $F 80 / 60$ fibres since this fibre has a larger aspect ratio. As other authors have also pointed out $[12,13]$, the $C_{f}-N_{f}$ relationship has high scatter since fibre distribution depends on many factors such as fibre geometric characteristics, concrete composition and cross section dimensions of the element. In concrete specimens reinforced with $F 65 / 60$ fibres, the smallest increase of $N_{f}$ occurred between $25 \mathrm{~kg} / \mathrm{m}^{3}$ and $35 \mathrm{~kg} / \mathrm{m}^{3}$ of fibres, which will justify some particularities of the behaviour observed in some series, as will be reported in another section.

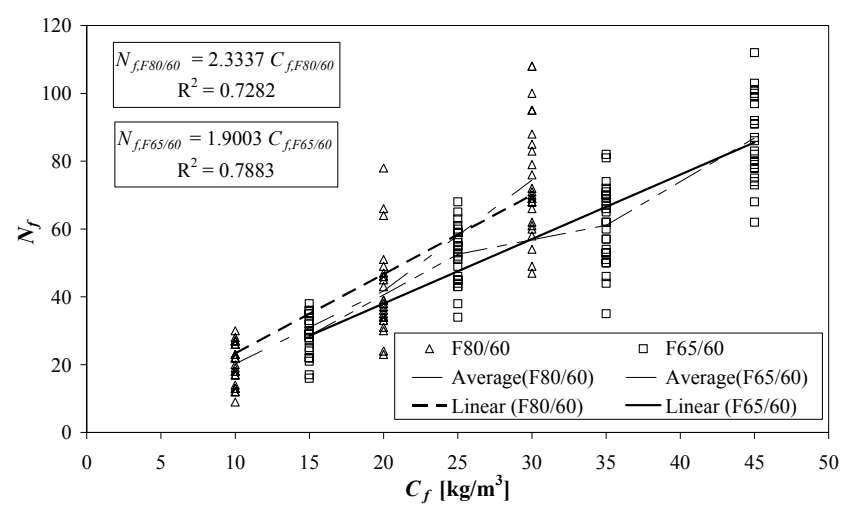

Fig. 3 - Relationship between the content of fibres, $C_{f}$, and the number of fibres on the specimen fracture surface, $N_{f}$.

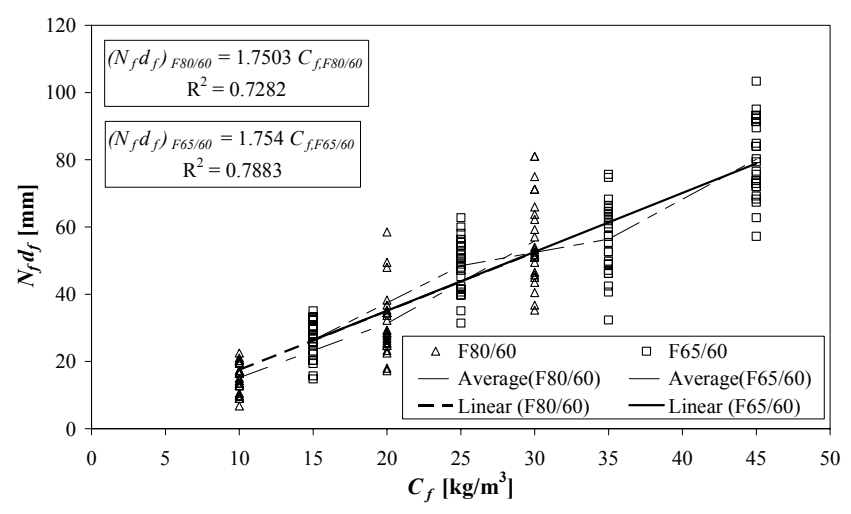

Fig. 4 - Relationship between the content of fibres, $C_{f}$, and the fibre reinforcement index, $N_{f} d_{f}$. 
Assuming that both fibres have similar embedment lengths at the specimen fracture surface, and that fibre-concrete interface of both fibre types have similar bond strengths, and that the influence of the fibre inclination is identical for both types of fibres, the tensile force resisted by fibres crossing the fracture surface becomes a function of both $N_{f}$ and $d_{f}$. The product $N_{f} d_{f}$ was designated as fibre reinforcement index, and Fig. 4 shows the relationship between $C_{f}$ and $N_{f} d_{f}$ to be similar for both types of fibres. This suggests that, considering the aforementioned assumptions, the flexural tensile strength parameters should be identical in the series reinforced with these fibre-types. This prediction will be confirmed in a later section.

\subsection{Equivalent and residual flexural tensile strength parameters}

Fig. 5 shows a linear trend between $f_{\text {eq, } 2}$ and $f_{e q, 3}$, and reveals that $f_{e q, 3}$ is slightly lower than $f_{e q, 2}$ indicating that, up to a deflection of $\delta_{3}$, the energy absorption capacity of the designed SFRC was maintained.

Therefore, it is enough to analyse the evolution of the $f_{e q, 2}$ since the observations attributable to $f_{\text {eq, }}$ can be also applied to $f_{\text {eq,3. }}$. A linear trend between $f_{R, I}$ and $f_{R, 4}$ was also obtained, with $f_{R, 4}$ being at about $93 \%$ of $f_{R, 1}$ (see Fig. 6). The scatter in the $f_{R, 1}$ - $f_{R, 4}$ relationship is, however, larger than the one in the $f_{e q, 2}$ -

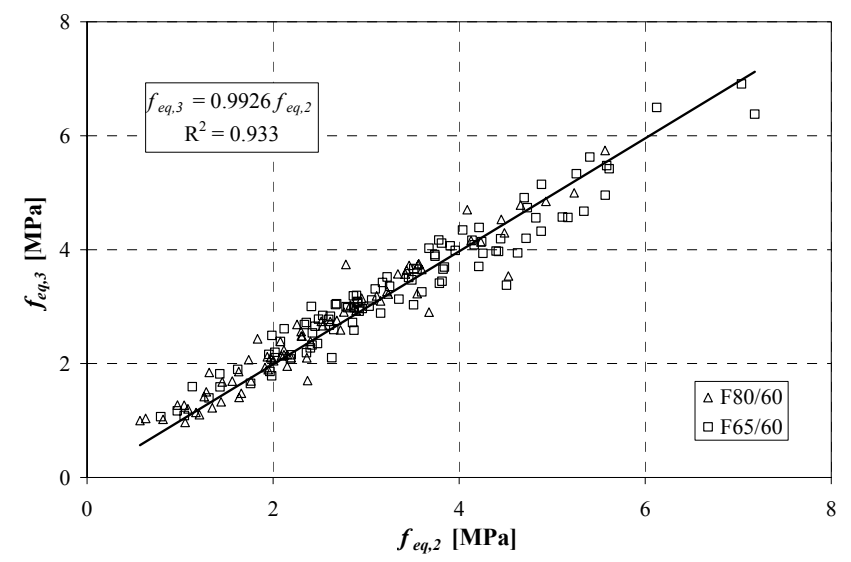

Fig. 5 - Relationship between $f_{e q, 2}$ and $f_{e q, 3}$.

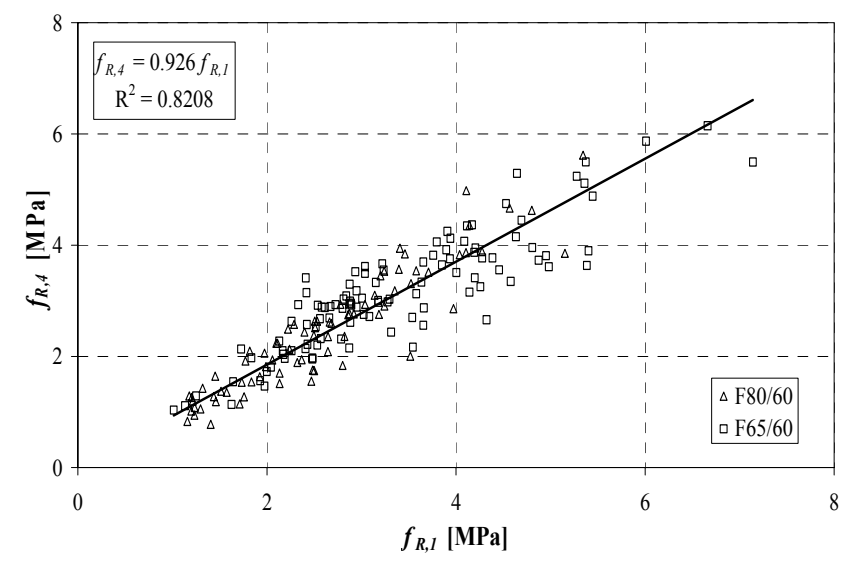

Fig. 6 - Relationship between $f_{R, I}$ and $f_{R, 4}$. $f_{\text {eq,3 }}$ relation, indicating that $f_{R}$ parameters are more susceptible to local irregularities of the $F$ - $\delta$ curve.

\subsubsection{Influence of the content of fibres}

Figs. 7 and 8 show that $f_{e q, 2}$ and $f_{R, 1}$ increase with $C_{f}$ in a linear fashion. A similar tendency was obtained for $C_{f}-f_{e q, 3}$ and $C_{f}-f_{R, 4}$ relationships. These figures reveal that, for equal fibre contents, $f_{e q, 2}$ and $f_{R, 1}$ values of specimens reinforced with $F 80 / 60$ fibres are slightly higher than the values of specimens reinforced with $F 65 / 60$ fibres. In specimens reinforced with $F 65 / 60$ fibres, for contents between $25 \mathrm{~kg} / \mathrm{m}^{3}$ and $35 \mathrm{~kg} / \mathrm{m}^{3}$, the increment of $f_{e q, 2}$ and $f_{R, I}$ was significantly less than the registered increase in the two other $C_{f}$ intervals. This can be justified by the smaller increment of $N_{f}$ between series reinforced with $25 \mathrm{~kg} / \mathrm{m}^{3}$ and $35 \mathrm{~kg} / \mathrm{m}^{3}$ (see Fig. 3). If a higher $N_{f}$ had been registered for $C_{f}=35 \mathrm{~kg} / \mathrm{m}^{3}$, as it would be expected, the $C_{f}-f_{e q}$ and $C_{f}-f_{R}$ relationships would be nearly the same for both series.

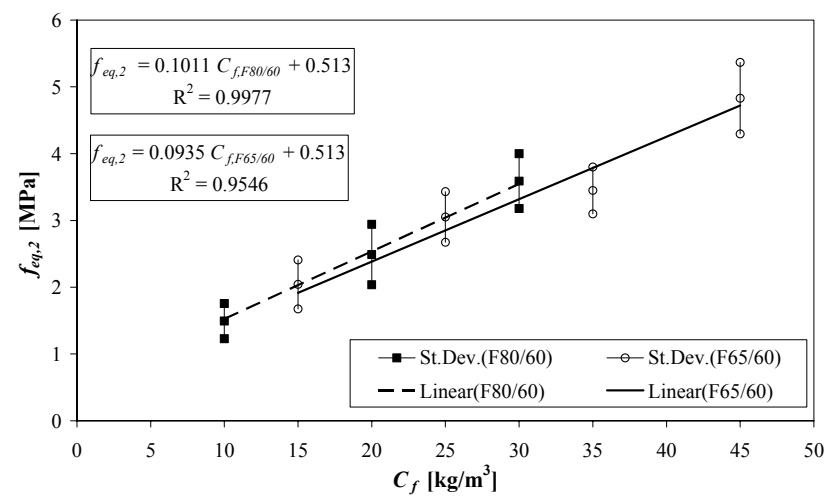

Fig. 7 - Relationship between $C_{f}$ and $f_{e q, 2}$.

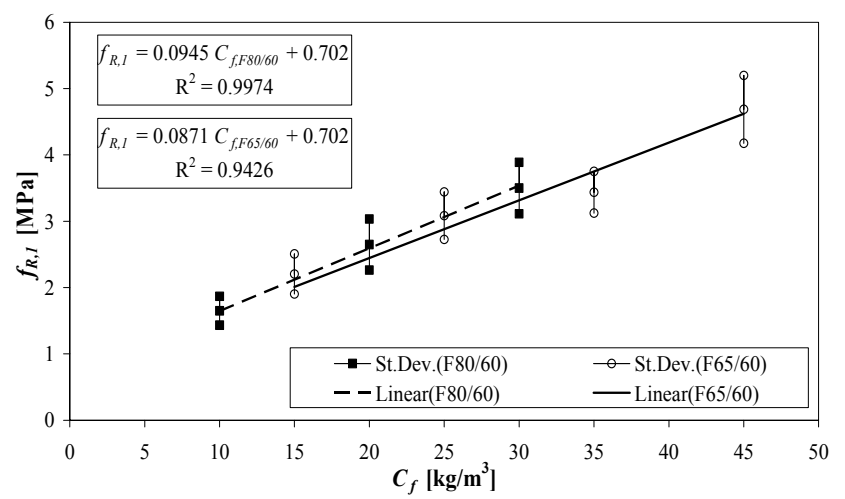

Fig. 8 - Relationship between $C_{f}$ and $f_{R, I}$.

\subsubsection{Influence of the number of fibres on the fracture surface}

Figs. 9 and 10 show that $f_{e q, 2}$ and $f_{R, 1}$ increase with $N_{f}$ in a linear trend, along with a high scatter of values for both relations. Similar trends were observed in the $N_{f}-f_{e q, 3}$ and $N_{f}-f_{R, 4}$ relationships. These figures confirm that, for the same number of fibres on the fracture surface, the $F 65 / 60$ fibre is more effective than the $F 80 / 60$ fibre in terms of $f_{e q}$ and $f_{R}$, since the $F 65 / 60$ fibre offers more resistance to pullout due to its larger diameter. 


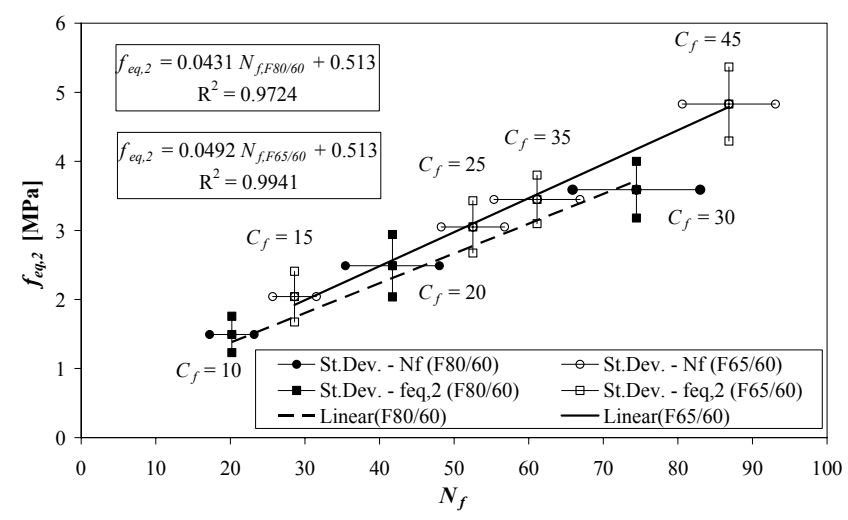

Fig. 9 - Relationship between the number of fibres on the fracture surface, $N_{f}$, and $f_{e q, 2}$.

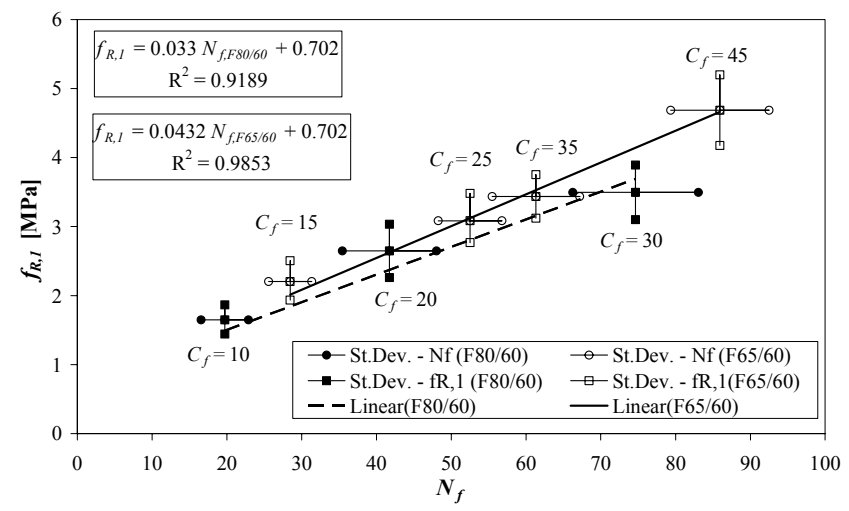

Fig. 10 - Relationship between the number of fibres on the fracture surface, $N_{f}$, and $f_{R, 1}$.

\subsubsection{Relationship between equivalent and residual flexural tensile strength parameters}

The relationships $f_{e q, 2}-f_{R, 1}$ and $f_{e q, 3}-f_{R, 4}$ are represented in Fig. 11. A strong correlation between equivalent and residual flexural tensile strength parameters is registered in series reinforced with the two utilised types of fibres, which agrees with results obtained by other authors [14].

\section{NUMERICAL RESEARCH}

\subsection{Numerical model}

Previous works $[13,15,16]$ have shown that, using a cross section layered model that takes into account the constitutive laws of the intervening materials, the kinematic and the equilibrium conditions, the force deflection relationship, $F-\delta$, of a three point bending notched beam test can be predicted from the moment curvature relation, $M-\chi$. This last relation is obtained for the two beam components comprised of two blocks behaving in a linear elastic fashion, connected by a non linear hinge of length $s$ where the main non linear behaviour due to cracking is concentrated (see Fig. 12). According to RILEM TC 162-TDF [15], $s$ is half of the net height of the fracture surface $\left(s=h_{s p} / 2\right)$.

The computational program developed in the present work includes the two approaches proposed by RILEM TC 162-TDF

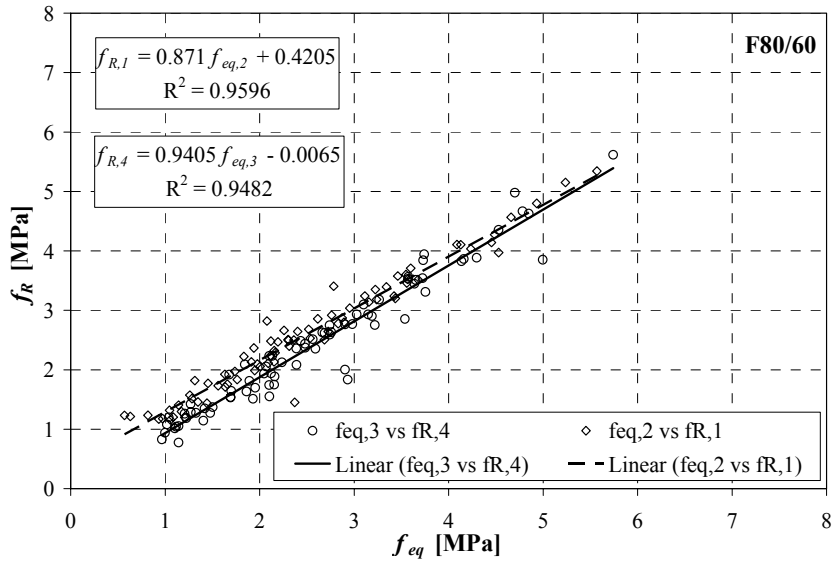

(a)

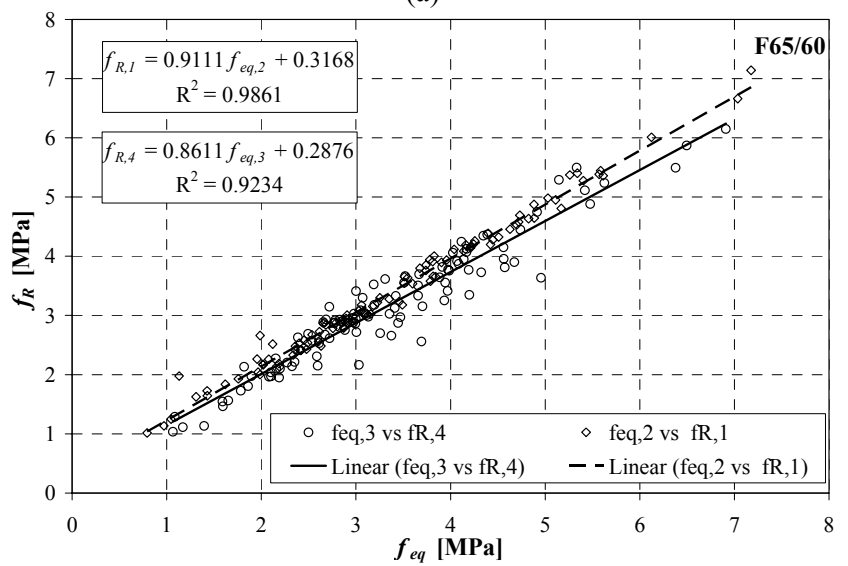

(b)

Fig. 11 - Correlation between $f_{e q}$ and $f_{R}$ in series reinforced with fibres (a) $F 80 / 60$ and (b) $F 65 / 60$.

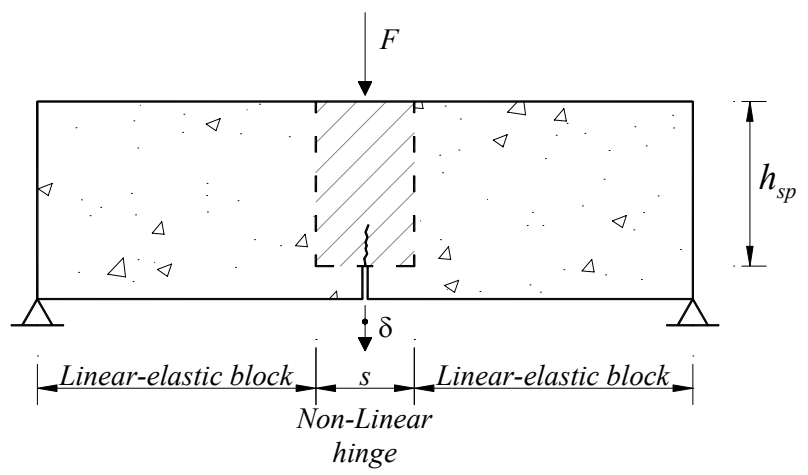

Fig. 12 - Specimen idealisation for model use.

to model the post cracking behaviour of SFRC. One of these is based on a stress-strain relationship designated by $\sigma-\varepsilon$-method [9], and the other, nominated by $\sigma-w$-method [15], uses the stress-crack opening relation represented in Fig. 13.

\subsection{The $\sigma-\varepsilon$-method}

\subsubsection{Modelling with the $\sigma-\varepsilon-m e t h o d$ of RILEM TC 162- TDF}

Fig. 14 represents the $\sigma-\varepsilon$ diagram proposed by RILEM TC 162-TDF [9] to model the uniaxial behaviour of SFRC. The points defining this diagram are determined from the 


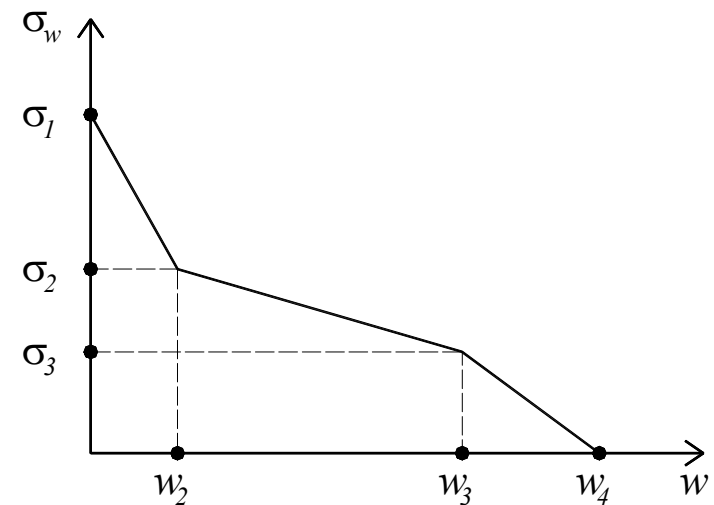

Fig. 13 - Stress crack opening diagram used in the $\sigma$-w-method.

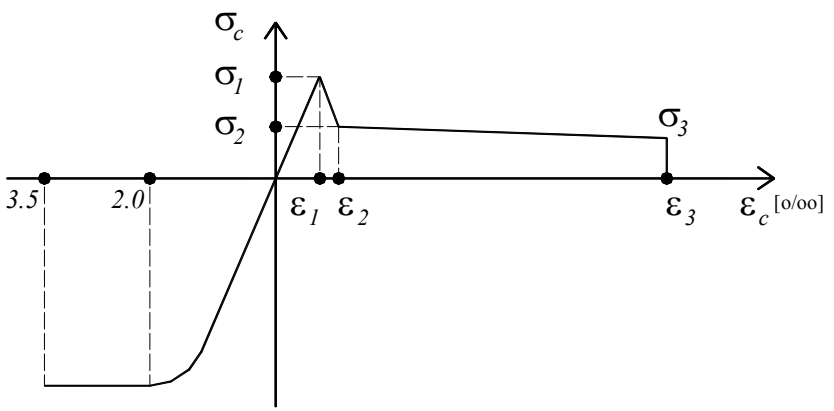

Fig. $14-\sigma-\varepsilon$ diagram for SFRC, according to RILEM TC 162-TDF [9].

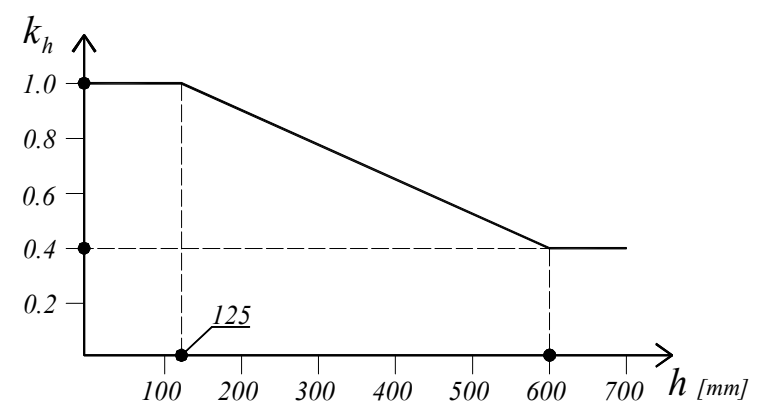

Fig. 15 - Size factor according to RILEM TC 162-TDF [9].

following relations:

$$
\begin{array}{lll}
\sigma_{l}=0.7 f_{c t m, f l}(1.6-d) & \sigma_{2}=0.45 f_{R, 1} \kappa_{h} & \sigma_{3}=0.37 f_{R, 4} \kappa_{h} \\
\varepsilon_{1}=\sigma_{l} / E_{c} & \varepsilon_{2}=\varepsilon_{1}+0.1 \% o & \varepsilon_{3}=25 \% o
\end{array}
$$

$E_{c}=9500\left(f_{c m}\right)^{1 / 3}$

where $f_{c t m} f l$ and $E_{c}$ are the SFRC average flexural tensile strength and Young's modulus (in $\mathrm{MPa}$ ), respectively, $d$ is the effective beam depth (in $\mathrm{m}$ ) and $\kappa_{h}$ is a parameter that intends to simulate the influence, on the post peak behaviour, of the element cross section height. The parameter $\kappa_{h}$ can be obtained from the graph represented in Fig. 15.

Using the $f_{c t m}, f$ and $f_{R}$ values obtained in the experimental tests and adopting the $\sigma-\varepsilon$ diagram represented in Fig. 14, the $F-\delta$ relationship of all series of specimens tested by the authors was evaluated. Fig. 16 represents the typical tendency observed in the numerical simulation of the series of the two types of fibres. Each experimental curve (thin line) is the average of the $F-\delta$ relationships recorded in the three

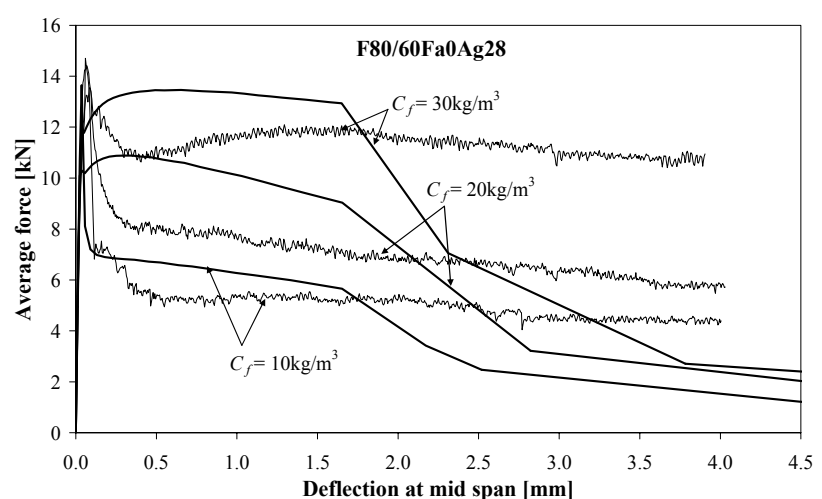

(a)

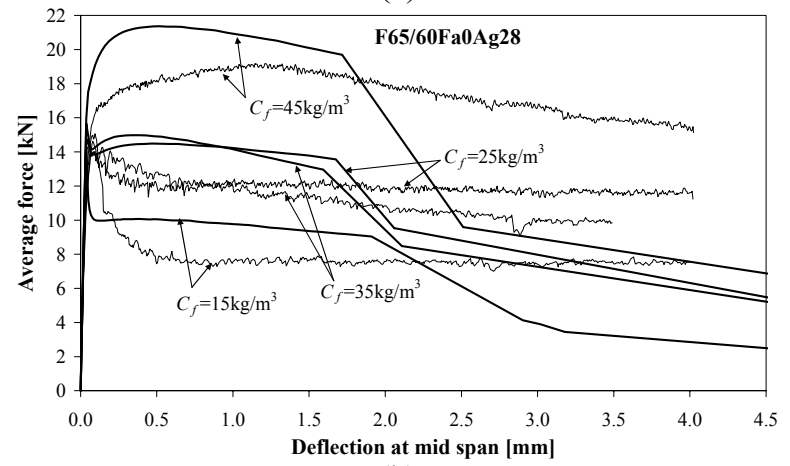

(b)

Fig. 16 - Comparison between experimental and numerical $F-\delta$ curves when using the $\sigma$ - $\varepsilon$-method proposed by RILEM TC 162 -TDF [9]: series with $0 \%$ of $F a$ and fibres (a) $F 80 / 60$ and (b) $F 65 / 60$.

specimens composing each series. Fig. 16 shows that, using the $\sigma-\varepsilon$ constitutive law proposed by RILEM TC 162-TDF, a higher residual force was predicted up to a deflection of about $1.8 \mathrm{~mm}$. At this deflection, the numerical model predicted a load decay, which was not observed in the experiments. This was due to the stress transfer loss of the layers exceeding the $\varepsilon_{3}$ strain (see Fig. 14). After this deflection, the numerical model predicted a residual strength lower than the one observed in the experimental tests. In general, just after peak load, the numerical model estimated a load decay larger than the one recorded in the experimental tests.

\subsubsection{Inverse analysis using the $\sigma$-E-method}

Due to the lack of precision obtained when using the $\sigma-\varepsilon$ method proposed by RILEM TC 162-TDF in the prediction of the $F-\delta$ relationship registered in the carried out tests, an inverse analysis was performed to evaluate the $\sigma_{i}$ and $\varepsilon_{i}$ values of the post cracking $\sigma-\varepsilon$ constitutive law assuring a minimum error in the simulation. The $\sigma_{i}, \varepsilon_{i}$ values that best fit the experimental $F-\delta$ relationships were obtained performing an inverse analysis with an optimisation procedure implemented for minimizing the error parameter:

err $=\left|A_{F-\delta}^{\exp }-A_{F-\delta}^{\text {num }}\right| / A_{F-\delta}^{\exp }$

where $A_{F-\delta}^{\exp }$ and $A_{F-\delta}^{\text {num }}$ are the areas situated below the experimental and the numerical $F-\delta$ relationship, respectively. The adequacy of the adopted numerical strategy is demonstrated in Fig. 17. The average of the error parameter, err, of the simulations performed in all the tested series was 

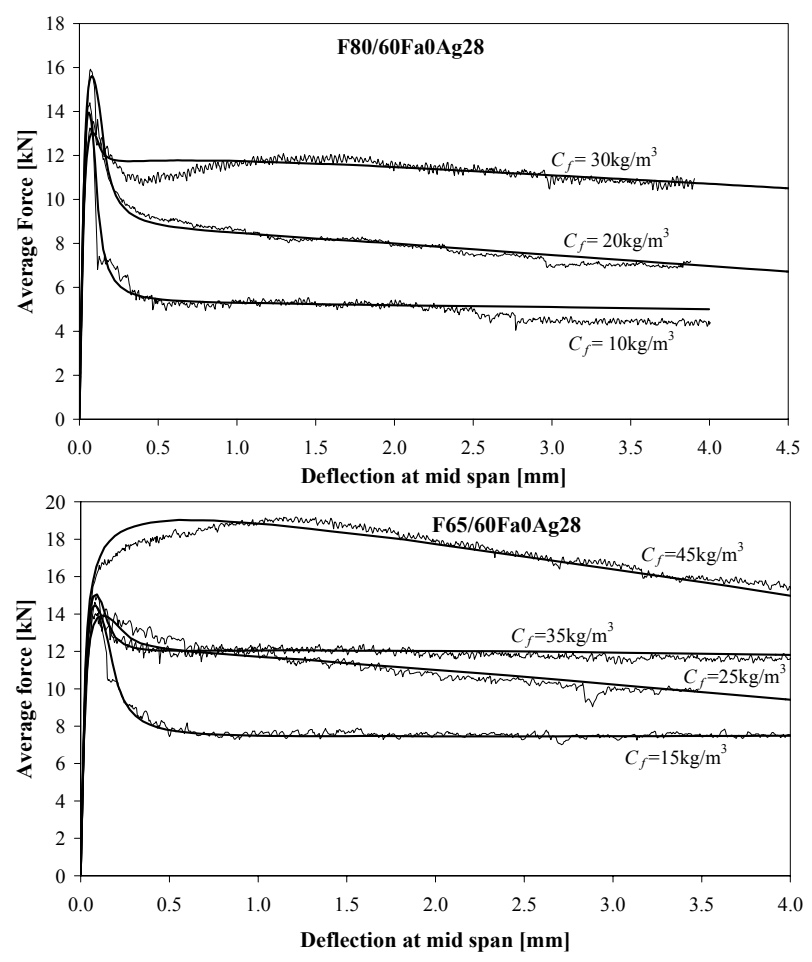

Fig. 17 - Comparison between experimental and numerical $F-\delta$ curves when using an inverse analysis based on the $\sigma$ - $\varepsilon$-method.

$2.43 \%$ with a standard deviation of $1.67 \%$, revealing that the proposed trilinear $\sigma-\varepsilon$ diagram is able to predict, with enough accuracy, the post cracking behaviour of the tested SFRC specimens.

The influences of both fibre type and fibre content on $\sigma_{i}^{I A} / \sigma_{i}^{R i l}$ and $\varepsilon_{i}^{I A} / \varepsilon_{i}^{R i l}$ ratios is represented in Fig. 18, where $\sigma_{i}^{R i l}, \varepsilon_{i}^{R i l}$ are determined according to the recommendations of RILEM TC 162-TDF [9], and $\sigma_{i}^{I A}, \varepsilon_{i}^{I A}$ are obtained in the inverse analysis. For the evaluation of the $C_{f}-\sigma_{i}^{I A} / \sigma_{i}^{R i l}$ and $C_{f}-\varepsilon_{i}^{I A} / \varepsilon_{i}^{R i l}$, all tested series were considered (series with $0 \%, 12.5 \%$ and $25 \%$ of cement replaced by $F a$, and tested at the age of 7, 28 and 90 days), which contributed to the high scatter registered on the values of $\sigma_{i}^{I A} / \sigma_{i}^{R i l}$ and $\varepsilon_{i}^{I A} / \varepsilon_{i}^{R i l}$ parameters. Fig. 18 reveals that $\sigma_{1}^{I A} / \sigma_{1}^{R i l}$ and $\sigma_{2}^{I A} / \sigma_{2}^{R i l}$ ratios remained lesser than the unit value for both fibre types and content of fibres used. This indicates that, using the recommendations of RILEM TC 162-TDF [9], excessively high values are estimated for $\sigma_{1}$ and $\sigma_{2}$. In series reinforced with $F 80 / 60$ fibres $\sigma_{1}^{I A} / \sigma_{1}^{R i l}$ increased with $C_{f}$, while in series reinforced with $F 65 / 60$ fibres, $\sigma_{1}^{I A} / \sigma_{1}^{R i l}$ was almost unaffected by the presence of the fibres up to $C_{f}$ of $35 \mathrm{~kg} / \mathrm{m}^{3}$. Above this fibre content, however, $\sigma_{1}^{I A} / \sigma_{1}^{R i l}$ increased with $C_{f}$. In series reinforced with $F 65 / 60$ fibres $C_{f}-\sigma_{2}^{I A} / \sigma_{2}^{R i l}$ remained practically constant at 0.78 , while in series reinforced with $F 80 / 60$ fibres $\sigma_{2}^{I A} / \sigma_{2}^{R i l}$ increased with $C_{f}$, mainly between $20 \mathrm{~kg} / \mathrm{m}^{3}$ and $30 \mathrm{~kg} / \mathrm{m}^{3}$.

For $\sigma_{3}^{I A} / \sigma_{3}^{R i l}$ parameter, an increasing trend with $C_{f}$ was obtained in series reinforced with $F 80 / 60$ fibres, while in series reinforced with $F 65 / 60$ fibres $\sigma_{3}^{I A} / \sigma_{3}^{R i l}$ decreased with the increase of $C_{f}$. For both types of fibres and for nearly all the considered $C_{f}, \sigma_{3}^{I A} / \sigma_{3}^{R i l}$ was lesser than the unit value, while
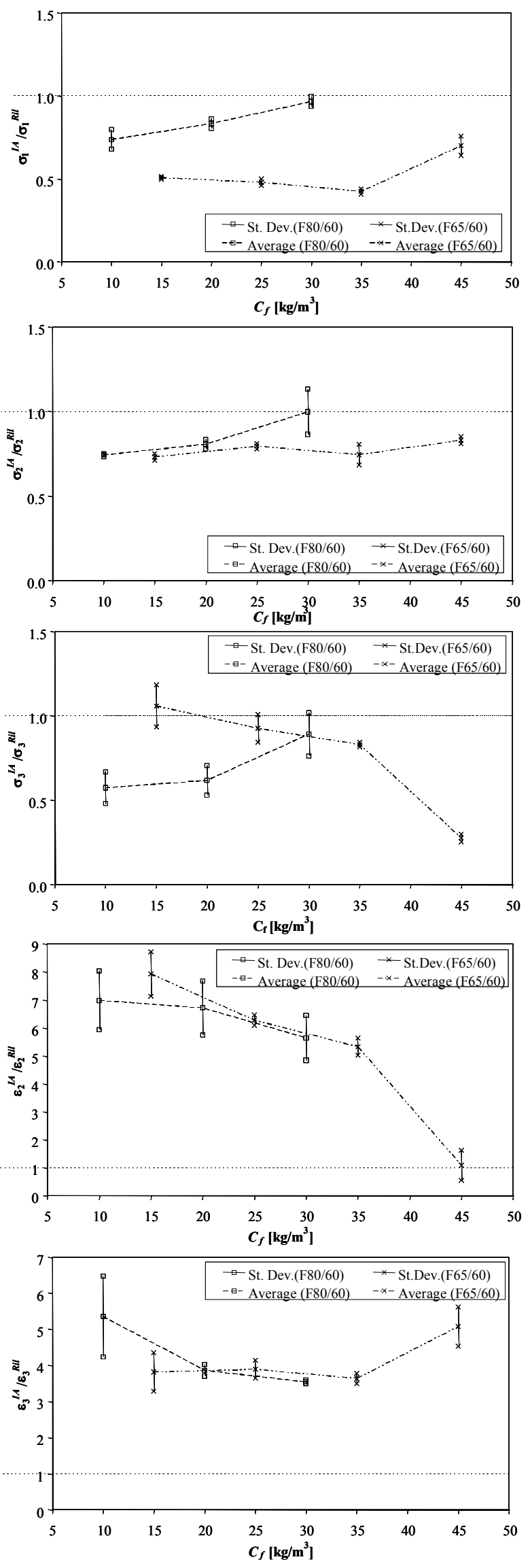

Fig. 18 - Influence of the $C_{f}$ on the $\sigma_{i}^{I A} / \sigma_{i}^{R i l}$ and $\varepsilon_{i}^{I A} / \varepsilon_{i}^{R i l}$ parameters obtained with the $\sigma$ - $\varepsilon$-method. 
$\varepsilon_{2}^{I A} / \varepsilon_{2}^{R i l}$ was larger than the unit value. With the increase of $C_{f}$, the $\varepsilon_{2}^{I A} / \varepsilon_{2}^{R i l}$ parameter approached the unit value. The values of $\varepsilon_{3}^{I A} / \varepsilon_{3}^{R i l}$ were in between 3.5 and 6.5.

The obtained results indicate the need to adjust the values of the parameters that define the post cracking $\sigma-\varepsilon$ constitutive law recommended by RILEM TC 162-TDF. New relations are included in Table 2. The $\sigma_{2}$ and $\sigma_{3}$ did not reveal the same evolution with $C_{f}$ in the series reinforced with the two types of fibres considered. Their evaluation as a direct dependency on the $f_{e q}$ or $f_{R}$ parameters is, consequently, a too simple approach which is chiefly responsible for the high standard deviation $\left(s_{d}\right)$ values obtained.

\begin{tabular}{|c|c|c|c|}
\hline \multicolumn{4}{|c|}{$\begin{array}{c}\text { Table } 2 \text { - New approach for defining the post } \\
\text { cracking } \boldsymbol{\sigma - \varepsilon} \text { diagram for SFRC }\end{array}$} \\
\hline$\sigma_{i}[\mathrm{MPa}]$ & $s_{d}{ }^{*}$ & $\varepsilon_{i}$ & $s_{d}{ }^{*}$ \\
\hline$\sigma_{l}=\mathbf{0 . 5 2} f_{c t m, f l}(1.6-d)$ & 0.09 & $\varepsilon_{l}=\sigma_{l} / E_{c}$ & - \\
\hline$\sigma_{2}=\mathbf{0 . 3 6} f_{R I} \kappa_{h}$ & 0.04 & $\varepsilon_{2}=\mathbf{1 . 2} \%$ o & 0.5 \\
\hline$\sigma_{3}=\mathbf{0 . 2 7} f_{R 4} \kappa_{h}$ & 0.10 & $\varepsilon_{3}=\mathbf{1 0 4} \%$ & 26 \\
\hline
\end{tabular}

\subsection{Inverse analysis using the $\sigma$ - $w$-method}

In an attempt at obtaining a $\sigma-w$ constitutive law adjusted for modelling the post cracking behaviour of the designed SFRC, an inverse analysis was carried out using the numerical strategy described in section 4.2.2. For this purpose, the $\sigma-w$ trilinear diagram represented in Fig. 13 was used. The values of the $\sigma_{i}$ and $w_{i}$ that have best fit the experimental $F-\delta$ relationships were obtained. A value of $10 \mathrm{~mm}$ was always assumed for $w_{4}$. Fig. 19 shows the performance of the strategy
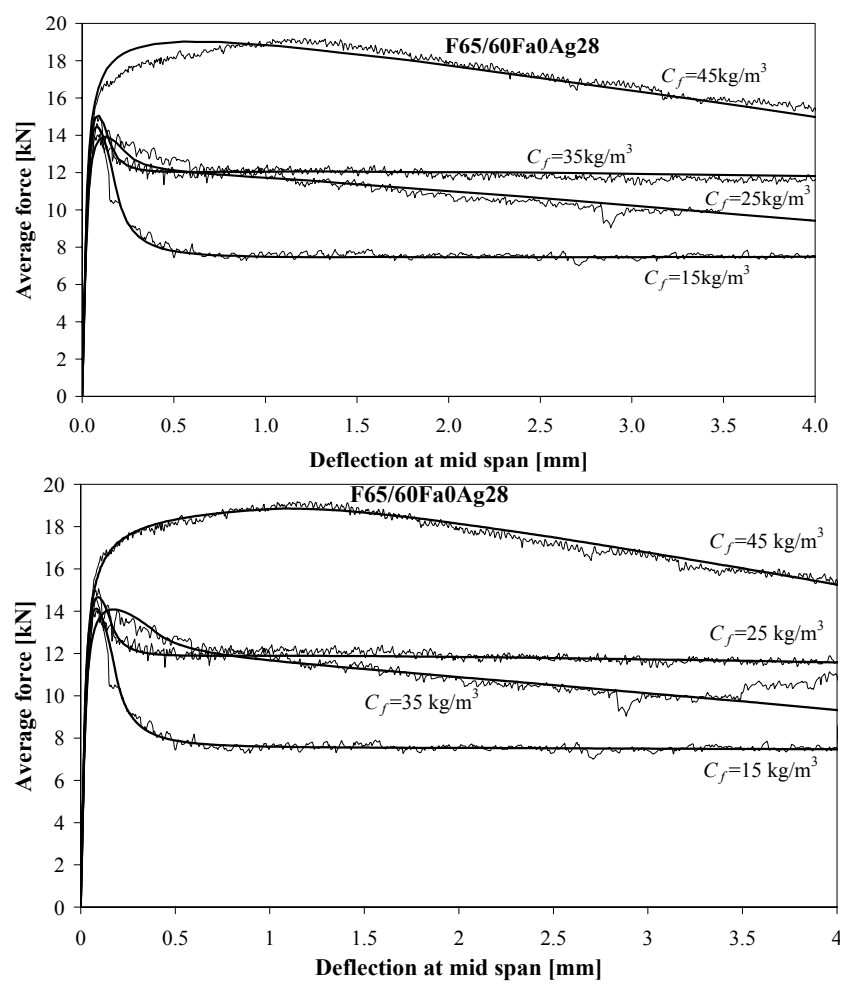

Fig. 19 - Comparison between experimental and numerical $F-\delta$ curves when using an inverse analysis based on the $\sigma-w$ approach. implemented. Similar performances were registered in the remaining tested series. The average of the error parameter, err, of the simulations performed in all tested series was $1.96 \%$ with a standard deviation of $0.86 \%$.

The obtained $C_{f}-\sigma_{i}^{I A}$ and $C_{f}-w_{i}^{I A}$ relationships are depicted in Fig. 20. Apart from series reinforced with $35 \mathrm{~kg} / \mathrm{m}^{3}$ of $F 65 / 60$ fibres, the $\sigma_{1}^{I A} / f_{c t m, f l}$ has slightly increased with $C_{f}$ in the remaining series. The exception might be related to the abnormal value of $N_{f}$ registered in this series. If a higher $N_{f}$ had been registered for $C_{f}=35 \mathrm{~kg} / \mathrm{m}^{3}$, as would be expected, $\sigma_{1}^{I A} / f_{c t m, f l}$ might have had a similarly increasing trend with $C_{f}$ in the series of the two used fibre types. These observations indicate that the content of fibres also influences the values of the $\sigma_{l}$. An exclusive dependency of $\sigma_{l}$ on $f_{c t m}, f$ is a too simplistic approach. Since $C_{f}-\sigma_{2}^{I A} / f_{R, 1}$ remained nearly constant, the $f_{R, 1}$ seems to be an appropriate parameter for defining $\sigma_{2}$. Series reinforced with $F 80 / 60$ fibres showed an increasing trend of $\sigma_{3}^{I A} / f_{R, 4}$ with $C_{f}$, while series reinforced with $F 65 / 60$ fibres did not reveal any well-defined tendency. In series reinforced with $F 80 / 60$ fibres, $w_{2}^{I A}$ slightly increased with $C_{f}$, while no tendency was observed in series reinforced with $F 65 / 60$ fibres. This might be related to the $N_{f}$ registered in the series of $F 65 / 60$ fibres, where for $35 \mathrm{~kg} / \mathrm{m}^{3}$ a $N_{f}$ value smaller than the one expected was obtained (see Fig. 3). The highest scatter in the $w_{2}^{I A}$ values was precisely observed in series reinforced with $35 \mathrm{~kg} / \mathrm{m}^{3}$ of $F 65 / 60$ fibres. For both types of fibres, $w_{3}^{I A}$ showed a decreasing trend with $C_{f}$ along with a considerable scatter.

With the values obtained for $\sigma_{i}^{I A}, f_{c t m, f l}$ and $f_{R}$, the following relations can be proposed:

$$
\begin{array}{lll}
\sigma_{1}=\mathbf{0 . 5} f_{\text {fctm }, f l} & \sigma_{2}=\mathbf{0 . 3 5} f_{R I} & \sigma_{3}=\mathbf{0 . 3 2} f_{R 4} \\
s_{d}=0.08 & s_{d}=0.02 & s_{d}=0.09
\end{array}
$$

Due to the reasons aforementioned, realizing that the influence of the size effect was not considered and taking into account the relatively high standard deviation values $\left(s_{d}\right)$, cautions should be taken in the use of these relations. To propose reliable values for $w_{i}$ more research should be conducted.

To perform a crack opening limit state analysis using material non linear finite element computing programs based on smeared crack models [17], the knowledge of a relationship between the post cracking strain, $\varepsilon^{p c r}$, and the crack opening displacement, $w$, is indispensable.

Based on the $\sigma-\varepsilon$ and $\sigma-\mathrm{w}$ diagrams that showed best agreement with the experimental $F-\delta$ relationships in the inverse analysis, the $\varepsilon^{p c r}-w$ relation represented in Fig. 21 was obtained. The authors are aware that this relationship is influenced by many factors, the most important of which is the structure size. While more extensive research is not available on this subject, the present analysis can make a contribution towards the aforementioned purpose. For crack opening values up to $10 \mathrm{~mm}$, the linear regression of the $\varepsilon^{p c r}-w$ points indicates that the length of the fracture process zone is close to the non linear hinge length $\left(s=h_{s p} / 2=62.5 \mathrm{~mm}\right)$. For crack opening of practical interest (less than $3 \mathrm{~mm}$ ), the length of the fracture process zone is about $74 \mathrm{~mm}$. This value is close to the 

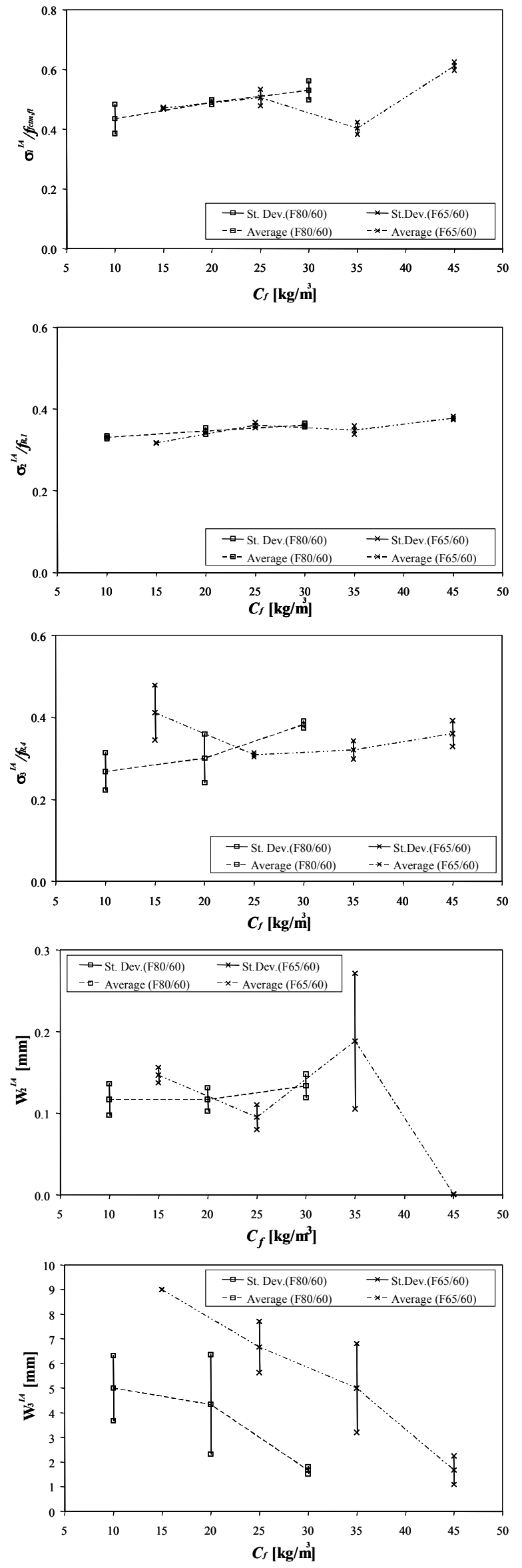

Fig. 20 - Influence of the Cf on the $\sigma_{i}^{I A}$ and $w_{i}^{I A}$ parameters obtained with the $\sigma$-w-method.

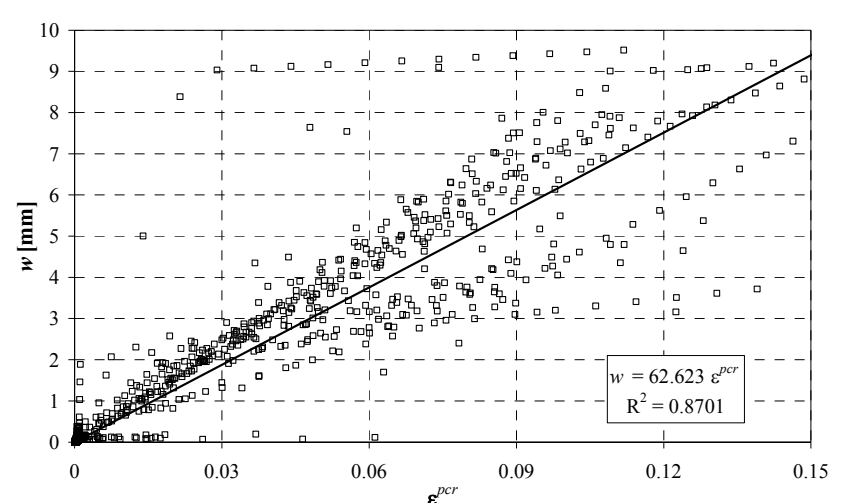

(a)

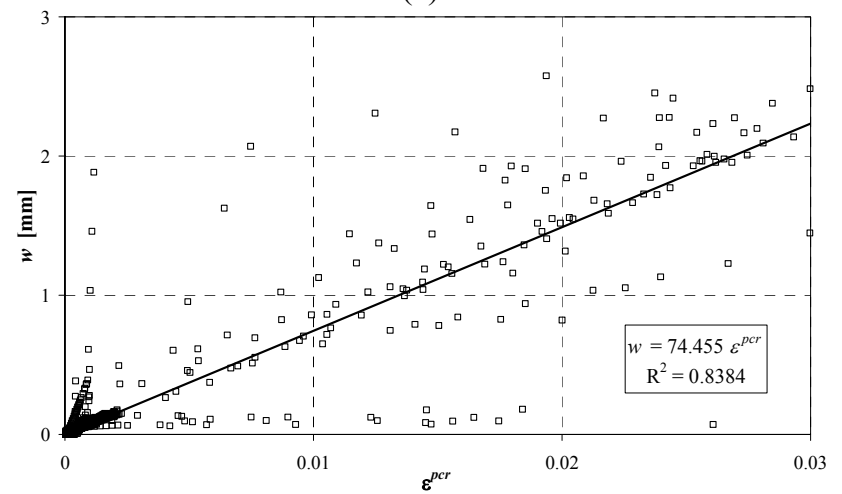

(b)

Fig. 21 - Relationship between the post cracking strain, $\varepsilon^{p c r}$, and the crack opening displacement, $w$, for a crack opening up to a) $10 \mathrm{~mm}$ and b) $3 \mathrm{~mm}$.

one obtained in a previous research [16], where specimens of other dimensions and reinforced with other type and contents of fibres were tested, and in which their corresponding $F-\delta$ relationships were also simulated numerically using a model similar to the one of the present work.

\section{CONCLUSIONS}

The post cracking behaviour of the designed SFRC was assessed carrying out three point notched beam tests according to the recommendations of RILEM TC 162-TDF. Based on the force deflection relationship, the values of the equivalent and residual flexural tensile strength parameters, $f_{e q}$ and $f_{R}$, were obtained. In the experimental program, two types of hooked ends steel fibres were used, where the fibre diameter, $d_{f}$, was the unique characteristic distinguishing them. Considering some reasonable assumptions, the tensile force resisted by fibres crossing the fracture surface of the specimen is dependent of the effective number of fibres crossing this surface, $N_{f}$, and of the fibre diameter, $d_{f}$. The product $N_{f} d_{f}$ was designated as fibre reinforcement index. The fibre reinforcement index was identical in the series reinforced with the types of fibres used, thereby justifying similar values of $f_{e q}$ and $f_{R}$ registered in these series. A strong correlation between $f_{e q}$ and $f_{R}$ was obtained with larger scatter in the $f_{R}$ values, indicating that $f_{R}$ parameters are more susceptible to local irregularities of the force-deflection curve, $F-\delta$. This suggests the use of the $f_{\text {eq }}$ concept instead of the $f_{R}$ concept. For the 
content of fibres, $C_{f}$, considered $\left(\leq 45 \mathrm{~kg} / \mathrm{m}^{3}\right)$, the $f_{e q}$ and $f_{R}$ increased with $C_{f}$ and with $N_{f}$.

A cross-section layered model, including trilinear $\sigma-\varepsilon$ and $\sigma$ $w$ diagrams for simulating the post cracking behaviour of the SFRC, was developed. Using the $\sigma-\varepsilon$ diagram proposed by RILEM TC 162-TDF, unsatisfactory predictions were obtained. Performing an inverse analysis, new parameters for defining the post-cracking $\sigma-\varepsilon$ diagram were determined. Using the $F-\delta$ relationships obtained from an inverse analysis carried out with $\sigma-\varepsilon$ and $\sigma-w$ methods, a relation between the post cracking strain, $\varepsilon^{p c r}$, and the crack opening displacement, $w$, was evaluated. This relationship can be useful in the evaluation of the crack opening when numerical strategies based on the $\sigma-\varepsilon$ approach are used. The length of the fracture process zone, $L p,\left(\varepsilon^{p c r}=w / L p\right)$ was in the range between half the specimen cross section height, $(h / 2=75 \mathrm{~mm})$, and half the distance between the tip of the notch and the top of the cross section $\left(h_{s p} / 2=62.5 \mathrm{~mm}\right)$.

\section{ACKNOWLEDGEMENTS}

The study reported in this paper forms a part of the research program "Cost competitive steel fibre reinforced concrete for industrial pavements "supported by FCT, POCTI/34793/99. The first author wishes to acknowledge the grant SFRH/BSAB/291/2002-POCTI, provided by FCT and FSE. The aggregates were generously supplied by "Pisonort -Lda", the cement by "Secil", the superplasticizer by MBT, the fly ash by "Central do Pego" and the fibres by "Bekaert NV". Special thanks for "Civitest Lda" for lending some test equipment.

\section{REFERENCES}

[1] ASTM C 1018, 'Standard test method for flexural toughness and first crack strength of fiber reinforced concrete (using beam with third-point loading (4.02)', American Society of Testing and Materials, Philadelphia, 1990, 637-644.

[2] Japan Society of Civil Engineers, 'Method of test for flexural strength and flexural toughness of fiber reinforced concrete', Standard, SF-4, 1984, 58-66.
[3] Gopalaratnam, V.S. et al., 'Fracture toughness of fiber reinforced concrete', ACI Materials Journal 88 (4) (July-Aug. 1991) 339-353.

[4] Banthia, N. and Trottier, J.-F., 'Test methods for flexural toughness characterization of fiber reinforced concrete: some concerns and a proposition', ACI Materials Journal 92 (1) (Jan.-Feb. 1995) 48-57.

[5] Banthia, N., and Trottier, J.-F., 'Concrete reinforced with deformed steel fibres, Part II: Toughness characterization', ACI Materials Journal 92 (2) (Mar.-Apr. 1995) 146-154.

[6] Vandewalle, L. et al., 'Test and design methods for steel fiber reinforced concrete. Recommendations for bending test', Mater. Struct. 33 (225) (Jan.-Feb. 2000) 3-5.

[7] Vandewalle, L. et al., 'Test and design methods for steel fiber reinforced concrete. Recommendations for $\sigma-\varepsilon$ design method', Mater. Struct. 33 (226) (Mar. 2000) 75-81.

[8] Vandewalle, L. et al., 'Test and design methods for steel fibre reinforced concrete - Final Recommendation', Mater. Struct. 35 (253) (Nov. 2002) 579-582.

[9] Vandewalle, L. et al., 'Test and design methods for steel fibre reinforced concrete - $\sigma-\varepsilon$ design method - Final Recommendation', Mater. Struct. 36 (262) (Oct. 2003) 560-567.

[10] Barros, J.A.O. and Antunes, J.A.B., 'Experimental characterization of the flexural behaviour of steel fibre reinforced concrete according to RILEM TC 162-TDF recommendations', Proceedings of the RILEM TC 162-TDF Workshop, Edited by B. Schnütgen and L. Vandewalle (March 2003) 77-89.

[11] Robins, P., Austin, S. and Jones, P., 'Pull-out behaviour of hooked steel fibres', Mater. Struct. 35 (251) (Aug. 2002) 434-442.

[12] Gettu, R. and Barragán, B.E., 'Direct tension test and interpretation', Proceedings of the RILEM TC 162-TDF Workshop, Edited by B. Schnütgen and L. Vandewalle (March 2003) $15-30$.

[13] Kooiman, A.G., 'Modelling steel fibre reinforced concrete for structural design', Ph.D. Thesis, Delft Univ. of Technology, 2000.

[14] Rosenbusch, J. and Teutsch, M., 'Shear design with $\sigma-\varepsilon$-method', Proceedings of the RILEM TC 162-TDF Workshop, Edited by B. Schnütgen and L. Vandewalle (March 2003) 105-117.

[15] Vandewalle, L. et al., 'Test and design methods for steel fiber reinforced concrete. Design of steel fibre reinforced using $\sigma-\omega$ method: principles and applications', Mater. Struct. 35 (249) (Jun. 2002) 262-278.

[16] Barros, J.A.O. and Sena-Cruz, J.M., 'Fracture energy of steel fibre reinforced concrete', Journal of Mechanics of Composite Materials and Structures 8 (1) (Jan.-Mar. 2001) 29-45.

[17] Barros, J.A.O. and Figueiras, J.A., 'Nonlinear analysis of steel fibre reinforced concrete slabs on grade', Computers \& Structures 79 (1) (Jan. 2001) 97-106. 